\title{
Tissue manipulation for peri-implant aesthetics: a case report
}

\begin{abstract}
When dealing with peri-implant tissue manipulation in aesthetic areas, there is always great expectation regarding the result. Depending on the clinical situation, different solutions can be used. This report presents an example of an approach that may favor the results of oral rehabilitation with dental implants. After implant installation in the region corresponding to teeth 15 and 16 , the patient complained of a sinking in the implanted region, causing an aesthetic defect. Grafting of connective tissue was performed to gain volume in the vestibular region, thus seeking harmony with the adjacent tissues, this technique was associated with the fixed provisional crowns on the implants, to create an emergency profile and gingival contour close to the natural. The approach was chosen based mainly on the volume and quality of the peri-implant tissue. For good predictability, factors such as soft tissue and hard peri-implant quality must be carefully evaluated. Coupled with a good aesthetic and functional prosthetic rehabilitation, will guide the way to a satisfactory result.
\end{abstract}

Keywords: Dental implants, Gingiva, Esthetics
Case Report

Volume 9 Issue 2 - 2018

\author{
Luís Ricardo Machado Magalhães,' Linéia \\ Tavares Teófilo, ${ }^{2}$ Danilo Rocha Dias, ${ }^{2}$ Ana \\ Luiza Lima Medeiros Paz,' Rafael da Silva \\ Caetano,' Luiz Evaristo Ricci Volpato',3 \\ 'Department of Dentistry, Mato Grosso Cancer Hospital, Brazil \\ ${ }^{2}$ Private Office, Brazil \\ ${ }^{3}$ Cuiabá Dental School, University of Cuiabá, Brazil
}

Correspondence: Luiz Evaristo Ricci Volpato, Cuiabá Dental School, University of Cuiabá, R. Estevão de Mendonça, 317, Cuiabá, Mato Grosso, Brazil,Tel 5565 98। |4-5244, Email odontologiavolpato@uol.com.br

Received: January 14, 2017 | Published: March 06, 2018

\section{Introduction}

The predictability of rehabilitative treatments with dental implants is not restricted to osseointegration alone. The professional should perform a detailed evaluation of soft as well as hard tissues, seeking the similarity between not only artificial and natural teeth, but gingiva regarding a natural pattern of color, contour and preservation of papillae. ${ }^{1,2}$ For this, different surgical and prosthetic options are available, which, together with biological factors, can provide good aesthetic result and long-term stability of the peri-implant tissues. ${ }^{3}$ For the selection of the ideal strategy, a detailed preoperative evaluation of the patient's smile, in many cases with anatomical limitations, and the knowledge necessary to choose the ideal intervention is important. The professional should consider the biological limitations of each patient, as well as technical limitations of treatment itself. In addition, one must decide the right moment to intervene knowing the predictability of each surgical and non-surgical resource. ${ }^{4}$ Thus, this work presents a case that addresses biological, surgical and non-surgical factors that may influence the repair and stability of peri-implant tissues in aesthetic areas, presenting features for different clinical situations depending on the quantity and quality of the gingival tissue.

\section{Case presentation}

A45-year-old female patient, after having undergone the installation of dental implants of the external hexagon type in the region of the right upper second premolar and first molar (Figure 1), presented the complaint of depression in the region of the implants, causing an aesthetic defect, visible when smiling (Figure 2). In the anamnesis, no relevant aspects were observed in the patient's previous and current medical history that could interfere in the diagnosis, treatment and prognosis of the intervention to be performed. The correction of the defect was performed after four months of the implants installation, using the technique of mucogingival surgery, in order to gain soft tissue in thickness. Prior to the surgical procedure, the patient received control of biofilm and orientation for maintenance of periodontal health. Then, a subepithelial connective tissue graft (SCTG) was performed using the roller technique. Local infiltrative anesthesia was performed by vestibular and palatine of the defect region using mepivacaine anesthetic $2 \%$ with vasoconstrictor. An incision was made with a $15 \mathrm{C}$ scalpel blade on the bony crest, further shifted to the palatine, and the dissection plane was crown-apical. Two other slightly divergent incisions were made in the palatal region to divide the epithelial flap. After splitting the flap, an incision at the base of the connective tissue attached to the periosteum was performed (Figure 3) to release the graft, which was moved to the receiving area (vestibular mucosa). The graft was folded under the vestibular flap (Figure 4) and stabilized with isolated suture at the base of the flap. Healing abutments were installed. The vestibular flap was repositioned around the abutments with the graft stabilized by the suture, also performed on the sides and at the base of the wound with interrupted stitches of resorbable Vicryl 5.0 (Figure 5). Compressive suture was performed on the palate over hemostatic sponge of hydrolyzed collagen (Figure 6). The postoperative period consisted of orientations to the patient regarding hygienic care, feeding, rest and prescription of analgesic (paracetamol $750 \mathrm{mg}$ ) and anti-inflammatory (nimesulide $100 \mathrm{mg}$ ). Chemical control of bacterial plaque was also prescribed by means of two 1-minute daily mouthwashes at twelve-hour intervals with $0.12 \%$ chlorhexidine digluconate. Patient returned to the postoperative period after seven days, and the suture was removed after 14 days. Patient was kept under control for 30 days, and she was referred for prosthetic rehabilitation after 4 months of surgery. With two months of proservation, tissue gain was observed in thickness (Figure 7). For gingival tissue conditioning, a provisional prosthesis was installed after three months of the mucogingival surgery (Figure 8). It was observed that, after the 6-month period of proservation, the tissue gain in thickness by the SCTG favored the vestibular emergency profile of the prosthesis and the new conformation of the gingival papillae (Figure 9) (Figure 10) (Figure 11). 


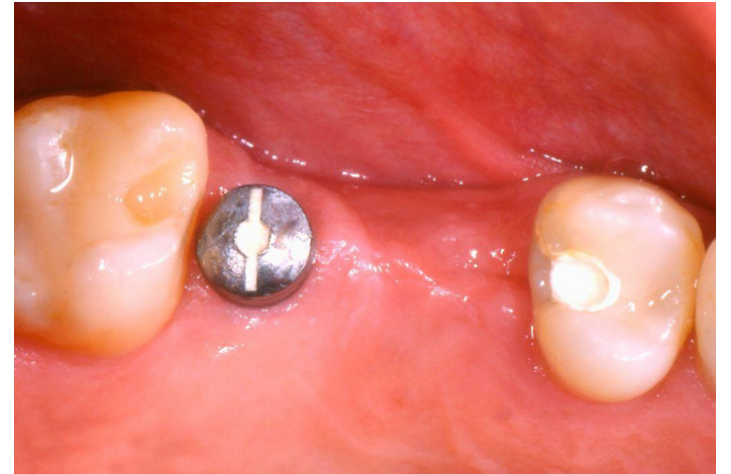

Figure $I$ Clinical aspect of the region showing the first molar implant healing abutment and the second premolar submucosal implant

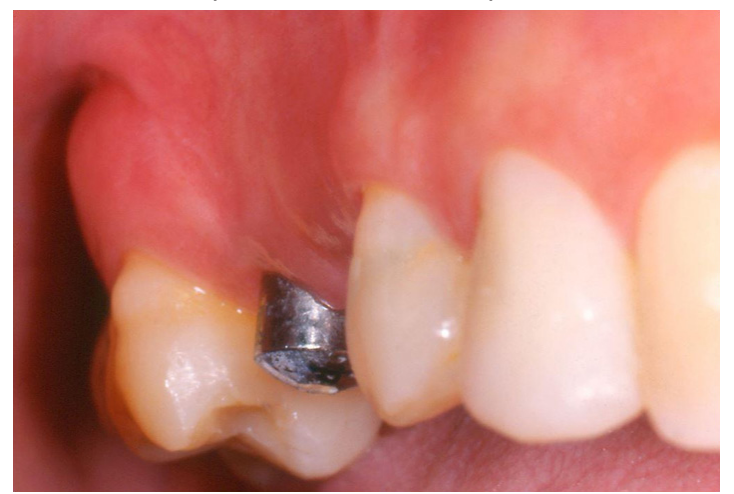

Figure 2 Tissue depressions in the buccolingual direction in the implants region.

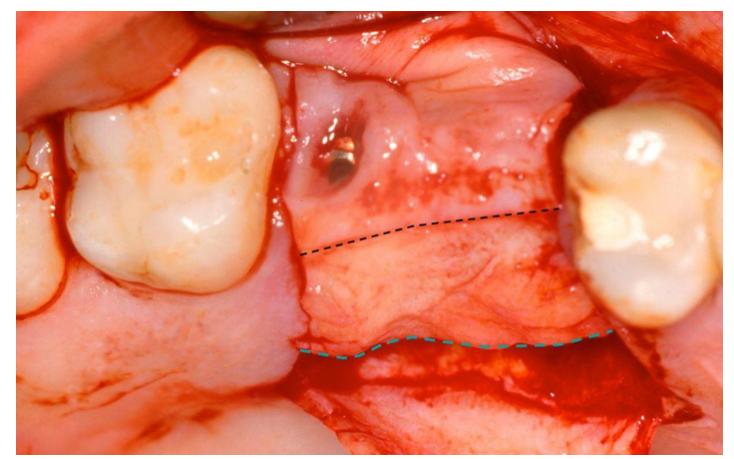

Figure 3 The black dashed line signals the first incision dividing the epithelial flap and the dashed line in blue signals the incision of the release of the conjunctive graft already displaced from its apical portion.

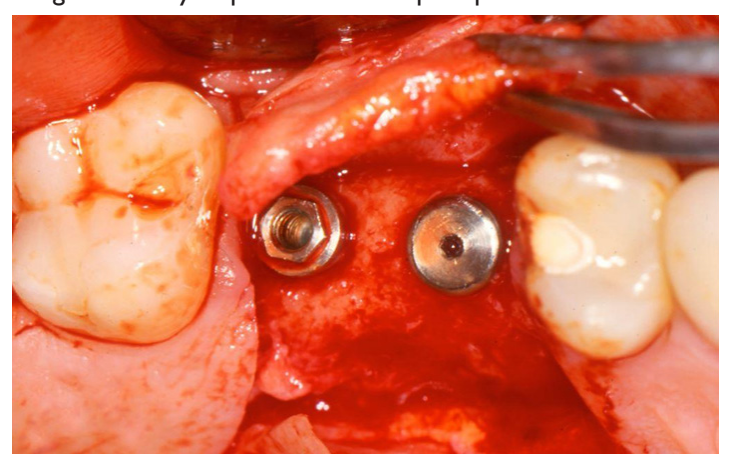

Figure 4 The connective tissue dislocated from its bed is folded under the vestibular flap.

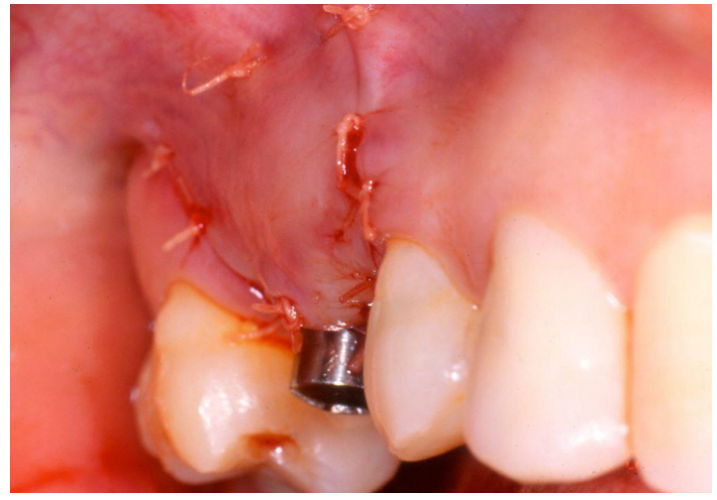

Figure 5 Suture with interrupted stitches after the installation of the healing abutments.

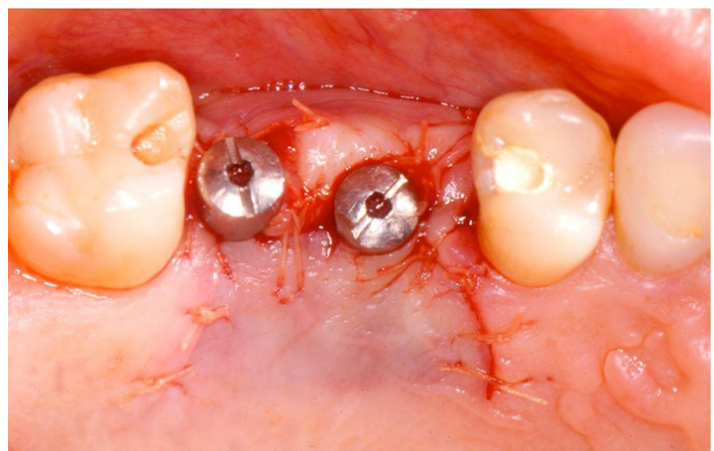

Figure 6 Compression suture in the palate region.

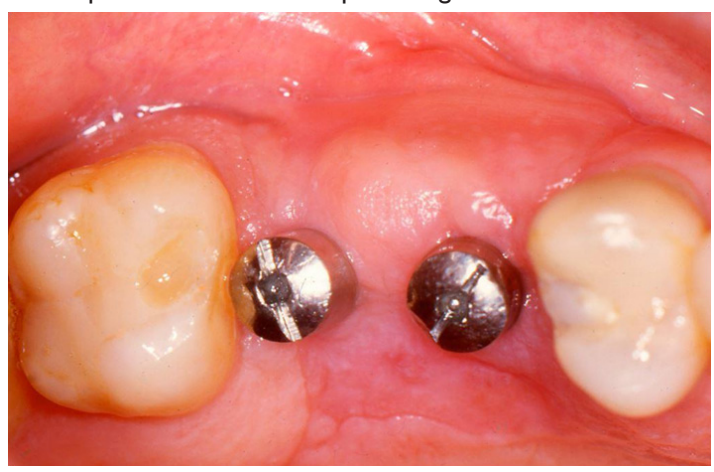

Figure 7 Tissue gain in thickness.

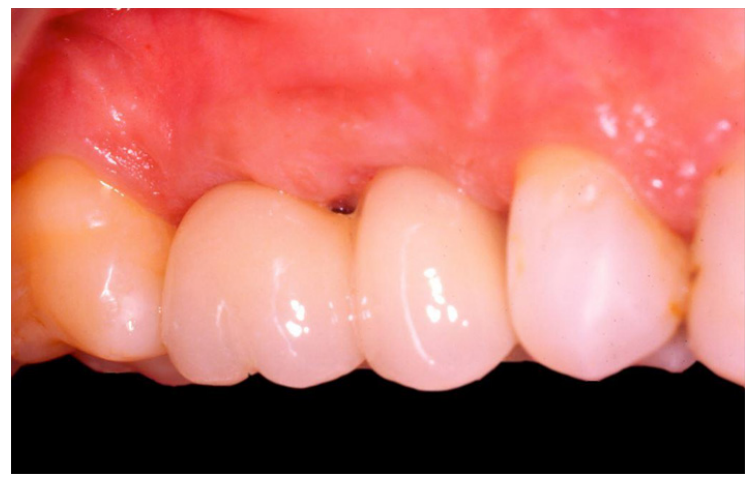

Figure 8 Installation of the provisional prosthesis for gingival conditioning, three months after SCTG. 


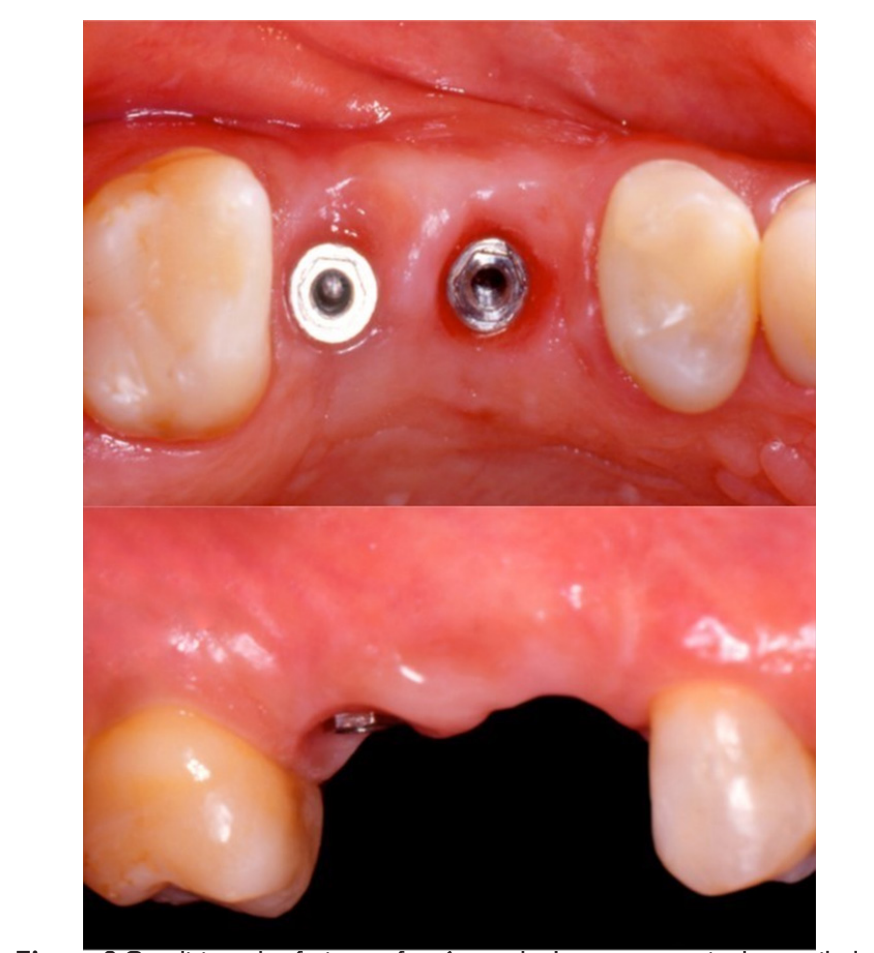

Figure 9 Conditioned soft tissue after 6 months. Improvement in the vestibular emergency profile of the prosthesis and neoconformation of papillae.

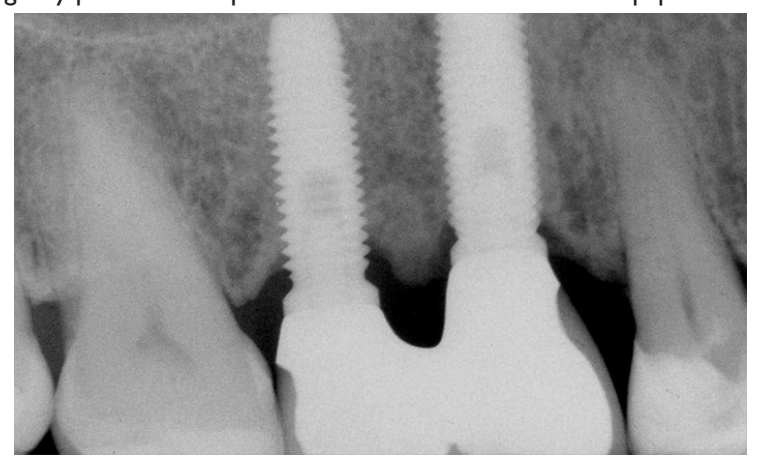

Figure 10 Final radiography after 6 months of SCTG.

\section{Discussion}

When it comes to peri-implant tissue manipulation in aesthetic areas, the dentist should have as reference the quality and quantity of the physiologic gingival tissues. Depending on the clinical situation, different solutions are recommended. The clinical case presented was an example of an approach that may favor the results of treatment with dental implants. This approach was chosen based mainly on the volume and quality of the peri-implant tissue. Other clinical studies ${ }^{5-7}$ have shown the importance of tissue thickness and bone volume in the peri-implant areas, related to the risk of peri-implant mucosal recession and filling of papillae.

In the clinical case, the patient had a vestibular-lingual defect or a vestibular depression in the implants area, which was corrected with the subepithelial connective graft technique four months after the implant installation, which favored the increase of soft tissue in thickness and, subsequently, the tissue conditioning with healing abutments. The use of implants with switching or supra-crestal

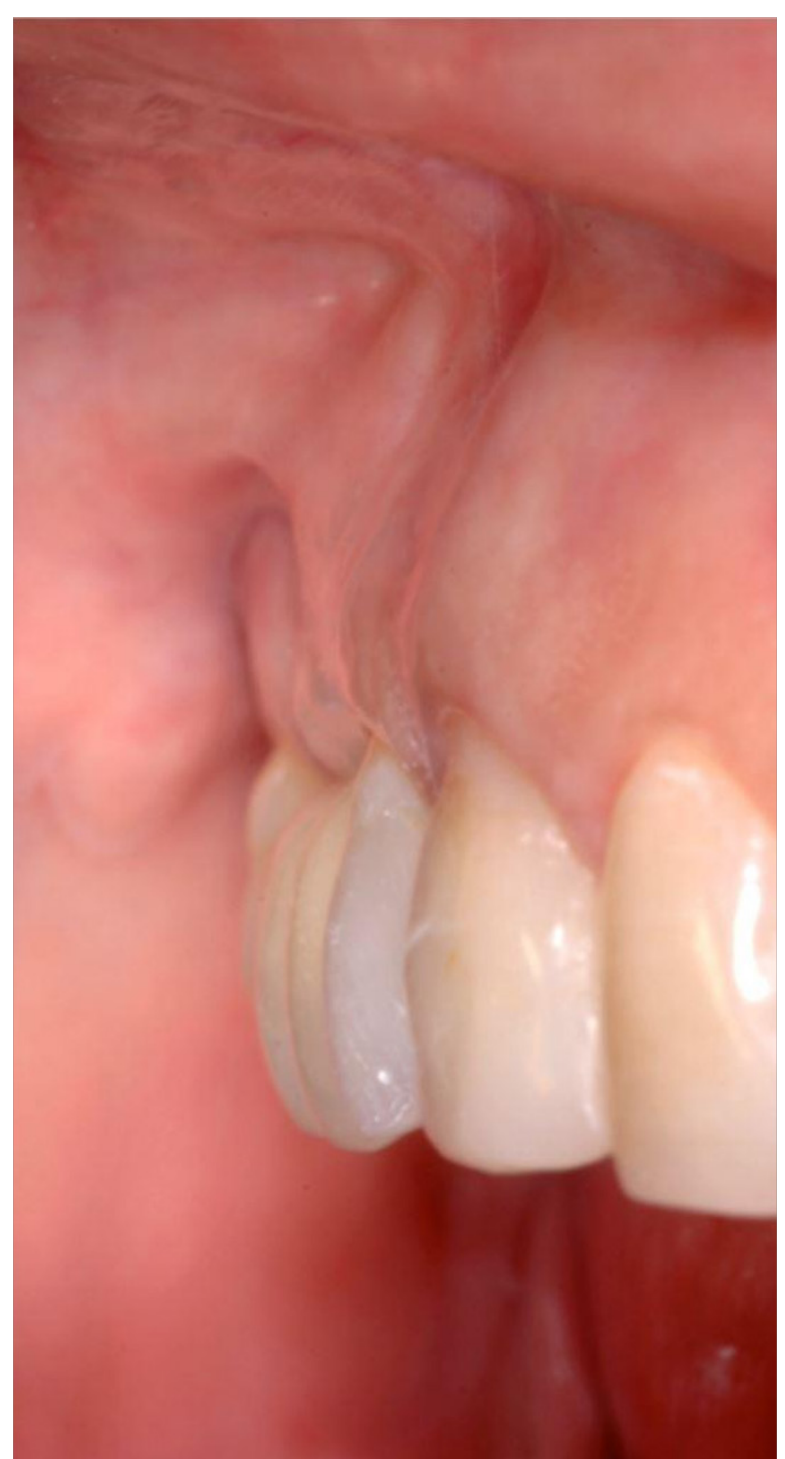

Figure II Final aspect.

platform might have minimized the amount of bone loss around the implants. However, implants with a traditional connection were used, without the perception that the type of platform could influence the levels of bone loss. Some researchers have advocated the use of switching platform implants to prevent bone loss. ${ }^{8}$ However, Lee et al. ${ }^{9}$ reported that the use of this type of platform failed to maintain bone crest levels in patients with a fine tissue biotype, presenting similar results to those implants with traditional connection. On the other hand, radiographic examination after the installation of the prostheses, three months after subepithelial connective tissue surgery, revealed that the distance between bone crest and interproximal contact favored the filling of the gingival papillae, which may have been influenced by the distance between the implants and also the greater ease of papillary restructuring between implants and teeth. ${ }^{6}$ In addition, the increase in the volume of the ridge prior to temporary tissue conditioning favored the vestibular emergency profile of the prosthesis, as well as the neoconformation of papillae and prosthetic crowns. Faced with limiting factors, such as the high or medium 
smile line, which attributes to the patient the high aesthetic risk, the professional will decide for a certain type of treatment depending on the tissue volume in height and thickness. The major defects of ridge height, in most cases, are much more difficult to correct with regenerative surgeries of bone and/or soft tissue grafts. In these cases, the professional can seek other solutions to enable treatment, especially if these defects are present in aesthetic regions. Although the implants of the reported clinical case have not been installed in fresh alveoli, several studies have shown that there are no significant differences between implants installed in fresh or healed alveoli relative to soft tissue repair. ${ }^{10}$ The quantity and quality of the gingival tissue are determining factors for planning the treatment with dental implants in aesthetic regions. The studies are not conclusive in relation to the routine surgical approach in aesthetic areas, but tend to defend the provisioning, whenever possible, in these areas. The mucogingival surgeries are a treatment option that allows better aesthetic results for the peri-implant tissues. Prosthetic solutions can be used successfully for bone and/or gingival tissue compensation when other treatment alternatives are not possible.

\section{Acknowledgment}

None.

\section{Conflict of interest}

The authors declare that they have no conflict of interest.

\section{Patient consent form}

Informed written consent was obtained from the patient.

\section{References}

1. Kazor CE, Al-Shammari K, Sarment DP, et al. Implant plastic surgery: a review and rationale. J Oral Implantol. 2004;3(4):240-54.

2. Bashutski JD, Wang H. Common Implant Esthetic Complications. Implant Dent. 2007;16(4):340-5.

3. Kan JYK, Rungcharassaeng K, Liddelow G, et al. Periimplant tissue response following immediate provisional restoration of scalloped implants in the esthetic zone: a one-year pilot prospective multicenter study. J Prosthet Dent. 2007;97(6):109-18.

4. Belser U, Buser D, Higginbottom F. Consensus statements and recomended clinical procedures regarding esthetics in implant Dentistry. Int J Oral Maxillofac Implants. 2004;19:73-74.

5. Evans CDJ, Chen ST. Esthetic outcomes of immediate implant placements. Clin Oral Impl Res. 2008;19:73-80.

6. Tarnow DP, Cho SC, Wallace SS. The effect of inter-implant distance on the height of inter-implant bone crest. $J$ Periodontol. 2000;71(4):546-48.

7. Somanathan RV, Simunek A, Bukac J, et al. Soft tissue esthetics in implant dentistry. Acta Medica. 2007;50(3):183-6.

8. Jang B, Pena ML, Eskow R, et al. The effect of implant design on crestal bone levels. Presented at the 23rd Annual Meeting of Academy of Osseointegration, Boston (EUA), 2008;1-4.

9. Lee A, Fu J, Wang H. Soft tissue biotype affects implant success. Implant Dent. 2011;20(3):38-47.

10. Rompen E, Raepsaet N, Domken O, et al. Soft tissue stability at the facial aspect of gingivally converging abutments in the esthetic zone: a pilot clinical study. J Prosthetic Dent. 2007;97(6 Suppl):119-25. 